In search of Eric

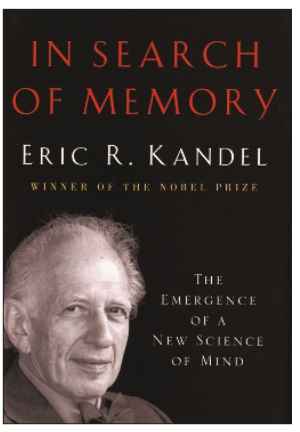

\section{In Search of Memory: The Emergence of a New Science of Mind}

\section{By Eric R Kandel}

W.W. Norton, 2006

$352 \mathrm{pp}$, hardcover, $\$ 29.95$

ISBN 0393058638

\section{Reviewed by Solomon H Snyder}

For well over 40 years, I have been privileged to interact with many talented neuroscientists, among whom Eric Kandel's intellect is unique. His insatiable thirst for understanding propels him to mastery of innumerable areas of the life sciences, ranging from cellular neurophysiology to molecular biology. In Search of Memory provides a glimpse into what makes Eric tick. This scientific autobiography is unique in interdigitating the author's personal and scientific odysseys while weaving into the narrative an extended history of multiple areas of neuroscience. All is presented with Eric's characteristic clarity so that most of the material will be accessible to any intelligent lay reader, yet illuminating to the professional. The narrative highlights Eric's skills as the finest teacher of neuroscience, author of the classic text in the field.

The book commences with Eric's childhood in pre-World War II Vienna, his father's close call with the Nazis, an eyewitness account of Kristallnacht and the family's escape to the United States. Eric's girlfriend at Harvard College, Anna Kris, was the daughter of two eminent psychoanalysts; this led to a long-term fascination with psychoanalysis. Accordingly, Eric entered New York University Medical School with psychoanalysis as an explicit goal. An elective at Columbia Medical School with the neurophysiologist Harry Grundfest launched Eric's romance with experimental neuroscience. Like many other young research-oriented physicians of the era, Eric's first extended research training came as part of 'military service' at the NIH in Bethesda, enabling Eric to do hippocampal neurophysiology under Wade Marshall. Though hooked on research, Eric still was infected with the psychiatry bug and undertook a full three-year residency at the psychoanalytically dominated Massachusetts Mental Health Center affiliated with Harvard Medical School. After this, Eric made a critical decision to devote himself full-time to laboratory research and to do research on a simple system, the sea slug Aplysia. Eric and his wife

The author is in the Department of Neuroscience, Johns Hopkins University School of Medicine, 725 North Wolfe Street, WBSB 813, Baltimore, Maryland 21205, USA.

e-mail: ssnyder@bs.jhmi.edu
Denise then proceeded to spend 14 months in Paris where he worked with Ladislav Tauc, a pioneer in the neurophysiology of Aplysia.

In the first five years of his independent laboratory at New York University, Eric used Aplysia to explore simple forms of learning and to work out the underlying neuronal circuitry. These efforts culminated with three consecutive papers published in the journal Science in 1970. He showed that Aplysia displays simple forms of learning such as habituation and dishabituation (sensitization) and mapped out the changes in the strength of specific synapses that explain these types of learning. Over the years he simplified the system so that he could monitor 'learning' in tissue culture with added serotonin replacing serotonergic neurons. Such systems permitted the application of molecular biology to learning/memory protocols. In more recent years, Eric has returned to studies of memory in mammals as exemplified by long-term potentiation in the hippocampus.

This brief synopsis fails to do justice to the richness of Eric's scientific story and his engaging tales of the giant personalities that advanced brain research over the past two centuries. An extended chapter is devoted to schizophrenia, antipsychotic drugs and the work of Arvid Carlsson, who first speculated that these agents act by blocking dopamine receptors. Some of Eric's most recent research explores the "dopamine hypothesis" of schizophrenia, which speculates that excess dopamine-like activity is involved in the disease's pathophysiology. Eric's team identified cognitive defects in mice with a genetic manipulation that leads to abnormally large numbers of dopamine D2 receptors. If the transgene for excess dopamine receptors is turned off in adult life, the cognitive deficits remain, implying an inexorable progress from neural aberrations in early life to schizophrenia in adulthood.

Eric ends the volume by offering words of advice to aspiring medical students interested in research. He advocates more experiments and less book learning. He emphasizes the role of chutzpah in making advances. He eschews the currently fashionable philosophy for successful grantgetting - don't do experiments unless you know the answer already, stick with what you know best, and only propose to do 'new experiments' that have already been completed. In contrast, Eric admonishes, "I also think it is important to be bold, to tackle difficult problems, especially those that appear initially to be messy and unstructured. One should not be afraid to try new things, such as moving from one field to another or working at the boundaries of different disciplines, for it is at the borders that some of the most interesting problems reside."

He also emphasizes the need to be a mensch, not just a scientific grind. Throughout the book he relates warm anecdotes of his son Paul and daughter Minouche and emphasizes other cultural aspects of life: "My work in science has always been greatly enriched by the passion that Denise and I share for music and art."

Few of the great scientists are sufficiently literate to convey to the general public what science is about. Eric is one of these few. Anyone interested in the science of the brain and in what it takes to do any type of science well must read this unique volume. 